\title{
Synthesis of Carbon Nano Flakes from Castor Seeds as Biogenic Precursor Using Single Zone CVD Method
}

\author{
Rohit Kumar ${ }^{*}$, Madhuri Sharon², A. K. Choudhary ${ }^{3}$ \\ ${ }^{I}$ Senior Research Fellow, Department of Botany \& Biotechnology, T. M. Bhagalpur University, Bhagalpur, India \\ ${ }^{2}$ Director, N.S.N. Research Centre for Nanotechnology and Bio-Nanotechnology, SICES College, Ambernath, \\ India
}

${ }^{3}$ Head, Department of Botany \& Biotechnology, T. M. Bhagalpur University, Bhagalpur, India

*Corresponding author: rohit.biotech05@gmail.com

\begin{abstract}
Castor seeds are non-edible oil rich plant product, with many medicinal properties. Carbon nano flakes being a new type carbon material were synthesized from castor seeds (as biological precursor) by single zone CVD method. During pyrolysis, Argon gas was used as a carrier gas, and temperature was maintained $800^{\circ} \mathrm{C}$ for an hour. Scanning Electron Microscopic (SEM) images confirmed the morphology of nano sized carbon flakes along with some nano-carbon fragments while XRD peaks showed the crystallinity of the carbon nano flake and RAMAN spectra of obtained carbon nano flakes revealed the presence of defects on its surface thus confirming its amorphous nature.
\end{abstract}

Keywords: Carbon nano materials, Castor seeds, Pyrolysis, RAMAN spectroscopy, SEM.

\section{Introduction}

Castor bean (Ricinus communis) seed is an important drought-resistant shrub. It belongs to the Family Euphorbiaceae [1], monotypic genus, Ricinus, and sub-tribe, Ricininae [2] which is indigenous to the south-eastern Mediterranean Basin, Eastern Africa. In tropical and sub-tropical countries like India it is widely grown [2]. Castor seed is rich of castor oil which has a wide variety of uses. The castor seeds are oil rich (40\%$60 \%$ ) especially triglycerides (ricinolein). They also contain low concentration of toxic ricin. Castor bean seeds are highly toxic to human and thereby, they are non-edible.

Use of plant derived products like camphor, oil, non-edible plant parts, resin etc. as precursor for the synthesis of Carbon Nano Material (CNM) have been made earlier [3]. Plant derived products as well as plant tissues contain oil, carbohydrate, protein etc. which are rich source of hydrocarbon. There are several reports on the preparation of Carbon Materials (CM) from agro-by-products or wastes, such as seeds of grape [4], cherry stones [4], straw of corn [5], hull of peanut [6], cotton stalk [7], peach stones [8].

In present decade the novel carbon materials have been the focus of attention by researchers because of their morphology, physical and chemical properties like carbon micro trees [9], mesoporous carbon [10], carbon nanohorns [11], coin-like carbon materials [12], carbon sphere [13], and so on. Carbon nano-flakes as a by-product of synthesized carbon nano-tubes were first reported by Ebbesen and Ajayan in 1992 [14]. Carbon nano-flakes have been prepared by novel synthesis methods for their application in past several years [15].

In the present investigation, we have attempted to synthesize carbon nano flakes from castor seeds used as a precursor by using single zone CVD method.

\section{Materials and Methods}

Precursors used were seeds of Ricinus communis (Castor), were procured from local market. Seeds were washed with distilled water (DW) and dried in an incubator at $60^{\circ} \mathrm{C}$ for $6 \mathrm{hrs}$ and then powdered in a mortar and pestle. Powder was stored till further use at room temperature.

Pyrolysis set-up: Single zone CVD furnace was used for pyrolysis of seeds. Quartz tube placed inside the furnace was used as a reactor. A flow meter was used for controlling the flow rate of carrier gas and bubblers were used for preventing the back suction into quartz tube during pyrolysis. The schematic of CVD set-up is presented in fig. 1. Known amount of the seed powder was taken as precursor into a quartz boat for pyrolysis. To make the furnace oxygen free Argon (Ar) gas was used. Pyrolysis was done at $800^{\circ} \mathrm{C}$ temperatures for $1 \mathrm{hr}$ duration.

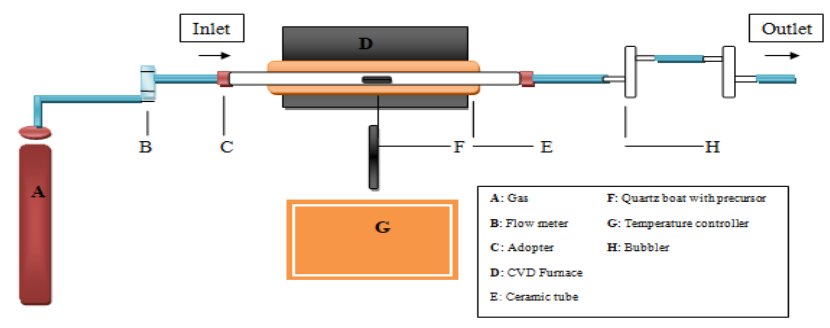

Fig. 1. A schematics of single zone CVD apparatus 
Pyrolysis of seed powder: $5 \mathrm{~g}$ crushed seed powder was taken in a quartz boat and kept inside the quartz tube then both the ends of furnace were fitted with adopters which were connected with inlet and outlet pipes. The desired carrier gas was purged inside the quartz tube at high flow rate $(150 \mathrm{ml} / \mathrm{min})$ for 15 minutes to remove the oxygen. Then gas flow was continued at slower rate $(25 \mathrm{ml} / \mathrm{min})$ during pyrolysis. After purging, the desired pyrolyzing temperature and duration of pyrolysis was set. Once the pyrolytic reaction was over, the furnace was allowed to cool down to room temperature. The pyrolyzed carbon material was subsequently collected from the boat.

Purification of carbon: Lumps of carbon collected from the quartz boat were powdered for acidic purification [16] to get rid of any metal or other residual materials. Mixture of carbonized seeds and $6 \mathrm{M} \mathrm{HCl}$ were thoroughly mixed and were kept for 2 hrs, and then filtered. The powder was then dried by keeping at $60^{\circ} \mathrm{C}$ for $6 \mathrm{hrs}$. Dried powder was stored for further investigations.

Characterization of carbon nano flakes:

The morphological observation of finally prepared CNM obtained from castor seeds as precursor was observed by Scanning Electron Microscope (SEM). SEM was examined by using 10-20 KeV with Hitachi 8-500 SEM and photographed with Kodak Tmax 100 film.

X-Ray Diffraction analysis mechanisms involve the constructive interference of monochromatic X-rays on a crystalline sampler. X-rays are generated by a cathode ray tube, filtered (ultrathin foils of Nickel or Copper to reduce low energy radiations) to produce monochromatic radiation, collimated (prevention of undesired exposure to reduce risk and improve image quality) to concentrate, and directed toward the sample. The sample preparation and loading in XRD analysis need to be handled carefully as analytical method. Hence, utmost care was necessary to avoid spillage and uneven loading and spreading. $500 \mathrm{mg}$ of powdered samples were weighed and taken in quartz mortar pestle and crushed to a very fine powder. A small amount of this powder was loaded to the sample holder with the help of micro-spatula and care was taken to apply uniformly and in the center of the holder as carefully as possible. Any spillage or uneven spreading can affect D G banding shifts, so necessary care was taken to use screens to apply the sample in the center of the sample holder. X-rays are generated XRD of carbon nano materials was performed with a powder X-ray diffractometer with $\mathrm{CuK} \alpha$ source to calculate the crystallographic parameters. The analysis was carried on Shimadzu MAXima_XXRD-7000.

Raman spectra are a spectroscopic technique which exploits the vibrational modes of molecules to peep into its structural details and identification. Raman spectroscopy is commonly used in analytical chemistry, where it provides a structural fingerprint, which molecules lead to molecular identification. In this study, dry powder form of seeds and CNMs were used, so no further preparation for Raman Spectra was needed. However, the glass slides used were selected properly and one Raman Spectra of the glass slide was run prior to sample run. The glass slides were washed and sonicated prior to use in analysis. Raman spectra were measured in a backscattering geometry using $\mathrm{Ar}$ ion laser $(488 \mathrm{~nm})$ at room temperature.

\section{Results and Discussion}

Through drying the moisture content of the seed was reduced. There was difference in weight observed after drying seeds in muffle furnace at $60^{\circ} \mathrm{C}$ for $8 \mathrm{hrs}$ (Table 1) Castor (Ricinus communis) seeds. Removal of moisture content was required in order to achieve dry seeds to be crushed into the powder form for further pyrolysis. Treatment at high temperature the carbonaceous compounds are completely broken down into simple carbon [17].

In order to synthesize carbon nano materials from caster seeds as plant precursors, four parameters were considered, they were - type of plant precursor (castor seeds), temperature $\left(800^{\circ} \mathrm{C}\right)$, carrier gas (argon) and time duration $(1 \mathrm{hr})$ for synthesis which in turn regulate the formation of nano materials and their nature.

The experimental study was carried out using castor seeds as precursor for the synthesis of carbon nano materials. Seeds were prepared as mentioned earlier. The processed precursor were weighed (5 gms each) before synthesis of nano materials through CVD method. The yield of carbon nano materials as obtained is mentioned in the table 2.

High temperature of pyrolysis is one of the significant parameters for the synthesis of CNM. Comparatively higher temperature has been observed suitable for the pyrolysis of precursors being rich in hydrocarbons. This stands as the reason for selecting temperature at $800^{\circ} \mathrm{C}$ in our experiments for CVD process. Ash formation is comparatively lower at high temperature and thereby, resulting in the formation of higher carbonization of precursors. Nearly complete breakdown of carbonaceous compound into simpler form of carbon occurs at considerably high temperature [17]. In previous investigations [18], [19], [20], it was observed that temperature range from $500^{\circ} \mathrm{C}$ to $900^{\circ} \mathrm{C}$ was suitable for the formation of CNMs.

During pyrolysis at higher temperature, carrier gases helps in removal of oxygen and its traces to restrict oxidation of CNMs Table 1

Percent removal of moisture from selected seeds

\begin{tabular}{|l|c|l|l|l|}
\hline S. No. & Non-edible seeds & Wt. of sample used & Moisture content (\%) & Crushed powder wt. used \\
\hline 1 & Ricinus cummins (Castor) & $10 \mathrm{gm}$ & $\sim 9.2 \%$ & $5 \mathrm{gm}$ \\
\hline
\end{tabular}

Table 2

Synthesis of carbon nano materials from castor seeds by single zone CVD method

\begin{tabular}{|l|l|l|l|l|l|l|}
\hline S. No. & Gas & Temperature $\left({ }^{0} \mathbf{C}\right)$ & Duration $(\mathbf{h r})$ & Precursor $($ Seed) & Precursor weight $(\mathbf{g m})$ & Yield (gm) \\
\hline 1 & $\mathrm{Ar}$ & 800 & 1 & Castor & 5 & 1.005 \\
\hline
\end{tabular}


Volume-3, Issue-10, October-2020

\section{IJRESM journals.resaim.com/ijresm | ISSN (Online): 2581-5792 | RESAIM Publishing}

Table 3

Showing the net weight of the Carbon nano materials derived from Castor seeds

\begin{tabular}{|l|l|l|l|l|l|l|l|}
\hline S. No. & Gas & Temp. $\left({ }^{\mathbf{0}} \mathbf{C}\right)$ & Duration (hr) & Precursor (Seed) & Precursor weight $(\mathbf{g m})$ & Yield (gm) & Yield after Purification (gm) \\
\hline 1 & $\mathrm{Ar}$ & 800 & 1 & Castor & 5 & 1.005 & 0.812 \\
\hline
\end{tabular}

produced. The removal of oxygen helps to maintain the static atmosphere favourable for further pyrolysis of CNMs in the CVD furnace [21], [22], [23]. Argon gas selected as carrier gases for the present work. The flow rate of gas also impacts the synthesis of CNMs. From the work of Khorrami et al. (2016) [24], it is evident that the higher flow rate of carrier gas adversely affects the synthesis of Carbon nano materials.

Reaction time of carbon source is one of the important factors to optimize the carbon nanotube synthesis conditions and product quality [25]. Duration of pyrolysis has an important role in the synthesis of CNMs. With the type of precursor used (castor seeds), duration of pyrolysis has different effects on the yield of the CNMs. Kumar et al. (2010) [19] has described the variation in the types of CNM with the variation in temperature and the duration of pyrolysis.

Depending upon the procedure applied for synthesis of CNM, different techniques for purification of products are being formulated. Ismail et al. (2008) [26] has described about the various methods for the purification of synthesized carbon nano materials. Since we followed the CVD process for synthesis of CNMs, some of the expected impurities were fullerenes, amorphous carbon, metal impurities from transition metal catalysts. The procedure used for purification was for removal of large graphite particles, elimination of catalyst particles and fullerenes (if any) by employing appropriate solvent [27]. We utilized preferably Hydrochloric acid for purification carbon nano materials [28].

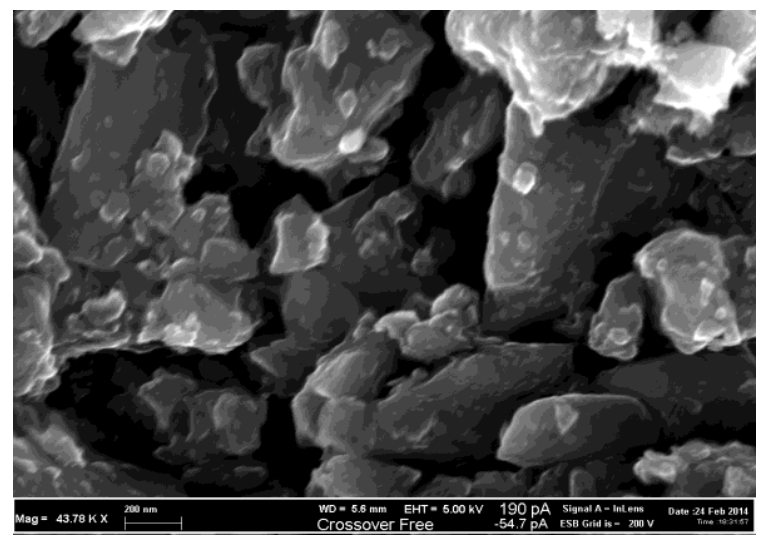

Fig. 2. SEM image showing Carbon nano flakes from pyrolysed castor Seeds

Amorphous carbon and metal catalyst impurities were washed off by purifying the resultant product with $10 \mathrm{ml}$ of $6 \mathrm{M}$ $\mathrm{HCl}$ for nearly 2 hours. Earlier, Yao et al., (2008) [29] used the similar technique to purify MWNTs. Further the remaining product was filtered to remove acidic content and then those were thoroughly washed (with DW) to get neutral $\mathrm{pH}$. Various Carbon nano material encapsulated with metal catalyst were also washed by using $\mathrm{HCl}$ as solvent. Continuing with the purification, the filtered was dried in the muffle furnace at $60^{\circ} \mathrm{C}$ for 6 hours. Once completely dried, weight measurements were made in order to analyze the net yield and also for further characterizations. Performing the carbon nano material synthesis from castor seeds, showed $0.812 \mathrm{gm}$ yield from 1.005 gm of impure CNM (table 3) while using Argon as carrier gas at $800^{\circ} \mathrm{C}$ for $1 \mathrm{hr}$ duration of pyrolysis.

The SEM micrograph of pyrolysed carbon nano materials (CNM) of Ricinus communis seeds (fig. 2) showed mixed size structure $(100-1000 \mathrm{~nm})$ with smaller fragments $(30-100 \mathrm{~nm})$. The morphology of CNM was found smooth flake like structures. In another investigation [30] had synthesized chain of carbon nano beads from castor seeds as precursor, however, utilizing Argon gas at $900^{\circ} \mathrm{C}$ with Iron as catalyst.

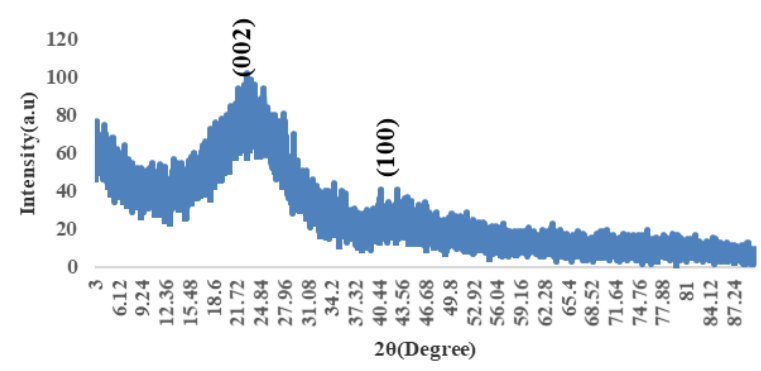

Fig. 3. XRD plot of carbon nano flakes obtained from pyrolysed castor seeds

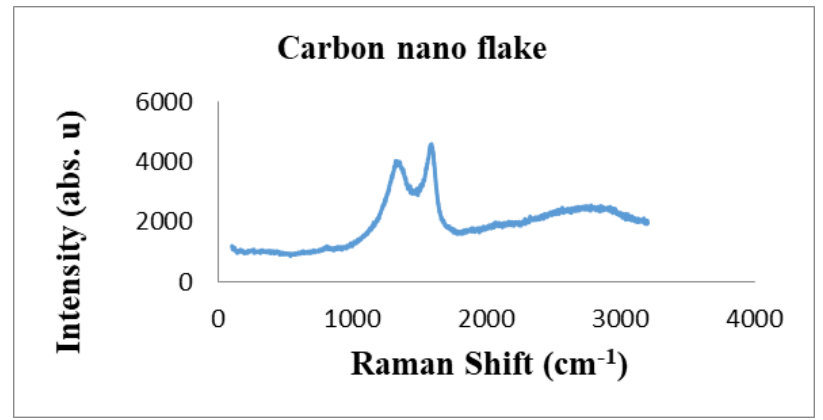

Fig. 4. Raman spectra of carbon flakes obtained from pyrolysed castor seeds

XRD graph of CNF (fig. 3) obtained from Castor seeds as a precursor showed a sharp peak at 22.36 degree (2Ө) for (002) and a blunt peak at 41.72 degree (2Ө) for (100). In this XRD plot, the growth of (002) peak is evidence of residual diamond structure and the growth of the (100) peak for graphite and so the observed intensity is due to both components. Similar graphical peaks were observed by Tripathi et al. (2013) [31] while working on Castor Oil. They observed peaks nearly at 23 (002) in all the three graphs which symbolized the presence of graphitic carbon. Additionally, the characteristic peak at $2 \Theta=$ 44 (100) confirms the structural association of nano material with Carbon [30]. The presence of Carbon in graphitic form is 
further supported by the work of Garcia-Gutterez et al. (2007) [32] who analyzed the carbon nano materials through XRD.

A Raman spectral analysis of carbon flakes obtained from castor seeds confirmed that the carbon obtained was of graphitic nature (fig. 4). Sharp and intense Raman peak of G-band observed at $1591 \mathrm{~cm}^{-1}$ with respect to the peak of D- band at $1359 \mathrm{~cm}^{-1}$ showed the presence of CNM in the form of flake like structure. An additional broad peak at $2815 \mathrm{~cm}^{-1}$ explains the $\mathrm{sp}^{2}$ hybridisation pattern; this feature corresponds to the overtone of the D-band. It is the $2^{\text {nd }}$ order two phonon process but sometimes clearly seen in the Raman spectra. A ratio of intensities of $\mathrm{I}_{\mathrm{D}} / \mathrm{I}_{\mathrm{G}}$ was calculated to be 0.884 , which denotes the presence of graphitic nature and purity of Carbon flakes. For improving the performance of carbon based materials for practical implications defects in graphic materials are of significance. Prasad et al., 2012 [33] obtained D band at 1330 $\mathrm{cm}^{-1}$ and $\mathrm{G}$ band at $1590 \mathrm{~cm}^{-1}$ of Raman spectra and also observed $\mathrm{I}_{\mathrm{D}} / \mathrm{I}_{\mathrm{G}}$ ratio was greater than 1 . They found edge plane like sites/defect similar to those of the outer graphene sheet of multi-walled carbon nanotubes (MWCNTs).

\section{Conclusion}

The Carbon nano flakes from biological precursor (castor seeds) have been synthesized by single zone chemical vapour deposition (CVD) furnace, which is an inexpensive source and the method can be further scaled up making it more viable way for obtaining bulk material of carbon nano flakes which was confirmed by using SEM, XRD and Raman spectra.

\section{Acknowledgment}

Authors wish to acknowledge the financial and laboratory support provided by the authorities of nsnRc, SICES college, Ambernath and also specially thanks to University Department of Botany, T. M. Bhagalpur University, Bhagalpur for laboratory.

\section{References}

[1] T.O. Akande A.A Odunsi, 11 2O.S. Olabode and 1T.K. Ojediran; Physical and Nutrient Characterisation of Raw and Processed Castor (Ricinus communis L.) Seeds in Nigeria; World Journal of Agricultural Sciences 8 (1): 89-95, 2012.

[2] R. Phillips, R. Martyn (1999). Annuals and Biennials. London: Macmillan, p. 106.

[3] 3. M. Sharon, K. Mukhopadhyay, K. Yase, S. Iijima, Y. Ando, X. Zhao; Spongy Carbon nanobeads - a new material Carbon, 36(506) (1998) 507511.

[4] D. Savova, E. Apak, E. Ekinci, F. Yardim, N. Petrova, T. Budinova. Biomass conversion to carbon adsorbents and gas. Biomass Bioenergy 2001;21:133-42.

[5] M. Lanzetta, C. Di Blasi. Pyrolysis kinetics of wheat and corn straw. J Anal Appl Pyrol 1998;44:181-92.

[6] B.S. Girgis, S.S. Yunis, A.M. Soliman. Characteristics of activated carbon from peanut hulls in relation to conditions of preparation. Mater Lett 2002;57:164-72.

[7] A. E. Putun, N. Ozbay, E.P. Onal, E. Putun. Fixed-bed pyrolysis of cotton stalk for liquid and solid products. Fuel Process Technol 2005;86:120719.

[8] W. T. Tsai, C.Y. Chang, S.L. Lee. Preparation and characterization of activated carbons from corn cob. Carbon 1997;35:1198-200.
[9] P. M. Ajayan, J.M. Nugent, R.W. Siegel, B. Wei and Ph. Kohler-Redlich, Nature, 404(2000)243.

[10] S. Álvarez, T. Valdés-Solís and A.B. Fuertes, Mater. Res. Bull., 43 (2008) 1898.

[11] C. M. Yang, Y.J. Kim, M, Endo, H. Kanoh, M. Yudasaka, S. Iijima and K. Kaneko, Nanowindow-Regulated Specific Capacitance of Supercapacitor Electrodes of Single-Wall Carbon Nanohorns, J. Am. Chem. Soc., 129(2007)20.

[12] D. S. Yuan, C.W. Xu, Y.L. Liu, S.Z. Tan, X. Wang, Z.D. Wei and P.K. Shen, Synthesis of coin-like hydro carbon and performance of pd catalyst support for methanol electrooxidation, Electrochem. Commun., 9((2007), 2473.

[13] C.W. Xu, Y.L. Liu and D. S. Yuan, Pt and Pd Supported on Carbon Microspheres for Alcohol Electrooxidation in Alkaline Media, Int. J. Electrochem. Sci., 2(2007), 674-680.

[14] Ebbesen, T., Ajayan, P., Large-scale synthesis of carbon nanotubes. Nature 358, 220-222 (1992).

[15] Y.H. Wu and B. J. Yang, Effects of Localized Electric Field on the Growth of Carbon Nanowalls, Nano Lett., 2(2002)355.

[16] Shingo Okubo, Takeshi Sekine, Shinzo Suzuki, Yohji Achiba, Kazuhito Tsukagoshi, Yoshinobu Aoyagi and Hiromichi Kataura Purification of Single-Wall Carbon Nanotubes Synthesized from Alcohol by Catalytic Chemical Vapor Deposition. Japanese Journal of Applied Physics, 43(2), 2004.

[17] G. Vishwanathan, S. Bhowmik \& M. Sharon (2018). Natural precursor for synthesis of carbon nano materials by chemical vapour deposition method process: A review, IJSR, 7 (2).

[18] M. Sharon, \& M. Sharon (2010). Carbon nanoforms and applications. New York: McGraw-Hill.

[19] 19. M. Kumar, \& Y. Ando (2010). Chemical vapor deposition of carbon nanotubes: a review on growth mechanism and mass production. Journal of nanoscience and nanotechnology, 10(6), 3739-3758.

[20] C. R. Bhattacharjee, \& A. Nath (2012). Chemical vapour deposition (CVD) technique and the synthesis of carbon nanomaterials (CNMs). Journal of Chemical and Pharmaceutical Research, 4(1), 706713.

[21] S. Paul (2012). Synthesis of carbon nanotubes from plant based precursors and their application in organic photovoltaic cells and biodiesel storage.

[22] A. B. Suriani, R. M. Nor, \& M. Rusop (2010). Vertically aligned carbon nanotubes synthesized from waste cooking palm oil. Journal of the Ceramic Society of Japan, 118(1382), 963-968.

[23] S. Kalaiselvan, M. Karthik, R. Vladimir, \& S. Karthikeyan (2014). Growth of Bamboo like Carbon Nanotubes from Brassica Juncea as Natural Precursor. J. Environ. Nanotechnol, 3(2), 92-100.

[24] S. A. Khorrami, \& R. Lotfi (2016). Influence of carrier gas flow rate on carbon nanotubes growth by TCVD with Cu catalyst. Journal of Saudi Chemical Society, 20(4), 432-436.

[25] G. Ortega-Cervantez, G. Rueda-Morales, \& J. Ortiz-Lopez (2005). Catalytic CVD production of carbon nanotubes using ethanol. Microelectronics Journal, 36(3-6), 495-498.

[26] 26. A. F. Ismail, P. S. Goh, J. C. Tee, S. M. Sanip, \& M. Aziz (2008). A review of purification techniques for carbon nanotubes. Nano, 3(03), 127143.

[27] S. P. Patole, P. S. Alegaonkar, H. C. Lee, \& J. B. Yoo (2008). Optimization of water assisted chemical vapor deposition parameters for super growth of carbon nanotubes. Carbon, 46(14), 1987-1993.

[28] N. Inami, M. A. Mohamed, E. Shikoh, \& A. Fujiwara (2007). Synthesiscondition dependence of carbon nanotube growth by alcohol catalytic chemical vapor deposition method. Science and Technology of Advanced Materials, 8(4), 292.

[29] Y. Yao, S. Zhang \& Y. Yan (2008, March). CVD synthesis and purification of multi-walled carbon nanotubes. In 2008 2nd IEEE International Nanoelectronics Conference, pp. 562-565.

[30] S. Gijare, S. Jebin, \& M. Sharon (2016). Impact of Catalyst on the Synthesis of Carbon Nano Materials from Castor Seeds by Chemical Vapour Deposition Method. Advanced Science Letters, 22(4), 1003-1007.

[31] S. Tripathi, M. Sharon, N. N. Maldar, J. Shukla, \& M. Sharon (2013). Nanocarbon synthesis using plant oil and differential responses to various parameters optimized using the Taguchi method. Carbon letters, 14(4), 210-217. 
[32] M. C. García-Gutiérrez, A. Nogales Ruiz, J. J. Hernández, D. R. Rueda \& T. A. Ezquerra (2007). X-ray scattering applied to the analysis of carbon nanotubes, polymers and nanocomposites.

[33] K. S. Prasad, M. C. Chuang, \& J. A. A. Ho (2012), Synthesis, characterization, and electrochemical applications of carbon nanoparticles derived from castor oil soot. Talanta, 88, 445-449. 